\title{
Protective Effect of Pomegranate Peel Extract against Diabetic- Induced Renal Histo-pathological Changes in Albino Rats
}

\author{
Ahmed T. G. Ahmed ${ }^{1}$, Saied K. M. Belal ${ }^{2}$, Amgad Gaber Elsaid Salem ${ }^{3}$

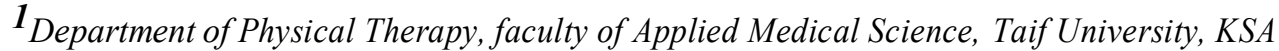 \\ Department of Anatomy, Faculty of Medicine, Assiut University, Egypt \\ ${ }^{2}$ Depratment of Anatomy, faculty of $d$ Medicine, Taif University, KSA \\ Department of Anatomy, Faculty of Medicine (Assiut branch), Al-Azhar University, Egypt

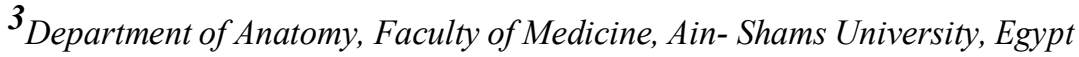

\begin{abstract}
Diabetes mellitus is a major public health problem worldwide. The overall prevalence of DM in adults in Saudi Arabia is 23.7\%. But, according to recent reports people living in Saudi Arabia could face a lifetime risk as high as 60 per cent of developing diabetes. Diabetes mellitus causes serious complications in many body systems. Diabetic nephropathy is one of the most debilitating complications of diabetes mellitus and it is a leading cause of death. Pomegranate is a native fruit to Al-Taif region. A number of biological activities such as antioxidant, antibacteria and antidiabetic have been reported for pomegranate extracts. The present study is conducted in order to demonstrate the protective effects of pomegranate peel extract against diabetic renal complications in streptozotocin-induced diabetic rats. 100 male of albino rats will be used and divided into three groups; the first group, normal or sham group; the second and third groups will be subjected to induction of diabetes. The third groups will treated with pomegranate peel extract orally. Biomedical analyses will be made at intervals through the trial. At the end of the trial (40 weeks) the animals will killed and the kidneys will sampled and prepared for histo-pathological, ultra-structural and immuno-histo-chemical examinations. Finally, Statistical analysis for numerical data will be made. Results revealed that administration of pomegranate peel extract leads to an improving effect on the renal parenchyma in diabetic kidney indicated by healed glomerular tuft, healed renal tubules and healed tubular interstitial epithelial cells with restoring the normal glomerular tuft structures as well as the normal glomerular capillary wall thickness and normally tubular basement membrane thickness. Also it showed significant improvement in the blood level of glucose, triglycerides and total cholesterol.

It was concluded that pomegranate peel extract has marked improving effects against diabetic renal complications. So, we advise use of pomegranate in human nutrition as table fruit or juice for its antihyperglycemic effects, antioxidant activities as well as its antihypertensive and anti-inflammatory action.

Keywords - pomegranate, diabetes, renal, histopathology
\end{abstract}

\section{INTRODUCTION}

Diabetes mellitus (DM) is a major public health problem worldwide; the incidence of the disease is gradually increasing in all regions of the world. The number of people suffering from DM is expected to rise to 2.21 billion by the year 2010 [1]. The overall prevalence of DM in adults in Saudi Arabia is 23.7\% [2]. But, according to recent reports by the American Diabetes Association, people living in Saudi Arabia and the Gulf could face a lifetime risk as high as 60 per cent of developing diabetes [3].

Diabetic nephropathy is the most common cause of end stage kidney disease, and the leading cause of death in diabetic patients [4 and 5]. The fundamental mechanism responsible for nephropathy in type 2 diabetes involves tubulo-interstitial fibrosis and glomerulo-sclerosis, caused among other processes by oxidative stress [6 and 7].

Pomegranate, Punica granatum L. (Punicaceae), is a native fruit to Al-Taif region. A number of biological activities such as anti-tumour, antibacterial and anti-diabetic have been reported for extracts from different parts of P. granatum [8-11]. Furthermore, antioxidant activity accompanied with radio-protective and anti-fibrotic properties of P. granatum peel extract have been demonstrated recently [12 and 13]. As well, a protective role of pomegranate was mentioned by. [14 and 15] on fatty liver in obesity through improvement of abnormal lipid metabolism.

On the other hand [16] reported that the inhibition of carbohydrate digestive enzymes and their phenolic content may contribute to the anti-hyperglycemic effects of pomegranate flower and peel, and support their claims in diabetes. Studies carried by [17] indicated that the methanolic extract of pomegranate peel has beneficial influences and could be able to inhibit Al-induced oxidative stress and histo-pathological alternations in liver and kidney of female rats, and these effects may be related to anti-apoptotic and antioxidant activities. 
Over the last decade, various studies have linked pomegranate (Punica granatum Linn), a fruit native to the Middle East, with type 2 diabetes prevention and treatment by [18]. This review focuses on current laboratory and clinical research related to the effects of pomegranate fractions (peels, flowers, and seeds) and some of their active components on biochemical and metabolic variables associated with the pathologic markers of type 2 diabetes. This review systematically presents findings from cell culture and animal studies as well as clinical human research. One key mechanism by which pomegranate fractions affect the type 2 diabetic condition is by reducing oxidative stress and lipid peroxidation.

This reduction may occur by directly neutralizing the generated reactive oxygen species, increasing certain antioxidant enzyme activities, inducing metal chelation activity, reducing resisting formation, and inhibiting or activating certain transcriptional factors, such as nuclear factor $\kappa \mathrm{B}$ and peroxisome proliferator-activated receptor $\gamma$.

Fasting blood glucose levels were decreased significantly by punicic acid, methanolic seed extract, and pomegranate peel extract. Known compounds in pomegranate, such as punicalagin and ellagic, gallic, oleanolic, ursolic, and uallic acids, have been identified as having anti-diabetic actions.

Furthermore, the juice sugar fraction was found to have unique antioxidant polyphenols (tannins and anthocyanins), which could be beneficial to control conditions in type 2 diabetes. These findings provide evidence for the anti-diabetic activity of pomegranate fruit; however, before pomegranate or any of its extracts can be medically recommended for the management of type 2 diabetes, controlled, clinical studies, are needed.

Antigen KI-67 is a nuclear protein that is associated with and may be necessary for cellular proliferation. Furthermore it is associated with ribosomal RNA transcription. [19] Inactivation of antigen KI-67 leads to inhibition of ribosomal RNA synthesis [20]. Also [21] investigated the chemopreventive effect of three natural extracts [pomegranate peel extract (PomPE), papaya peel extract (PapPE) and seaweed extract (SE) against AOM-induced oxidative stress and carcinogenesis in rat colon.

The present study is conducted in order to demonstrate the protective effects of pomegranate peel extract against diabetic renal complications in streptozotocin-induced diabetic rats, as one of the edible natural products that may have more potent and safe preventive and therapeutic effects.

\section{Materials And Methods}

\section{ANimals:}

100 male Sprague-Dawley rats ( 8 weeks old, weighing between 250 and 300 g.) will be used. The animals will be fed on standard laboratory chow and will be allowed free access to water in an air-conditioned room with a 12 hour light/12 hour dark cycle.

\section{Induction of diabetes:}

After 12 hours of fasting; the animals of model groups receive a single $60 \mathrm{mg} / \mathrm{kg}$ intraperitoneal injection of streptozotocin (STZ) dissolved in $0.05 \mathrm{ml} / 1$ sodium citrate buffer, $\mathrm{pH} \mathrm{4.5}$. Control (sham, nondiabetic) animals are fasted and received citrate buffer alone. After 24 hours, animals with blood glucose levels greater than $250 \mathrm{mg} / \mathrm{dL}$ are considered diabetic.

\section{Preparation of pomegranate peels extract:}

Fresh mature Punica granatum L. (Punicaceae) fruits are used. The taxonomic identity of the plant will be made by the Biology department, College of Science, Taif University. For extraction purpose, a peel is removed and dried in shade for 10 days before grounding.

Extract preparation is modified from [22]. The grounded material $(50 \mathrm{~g})$ is shaken in $500 \mathrm{ml}$ of absolute methanol for $24 \mathrm{~h}$ at room temperature, followed by filtration through four layers of gauze. The filtrate is centrifuged at $8000 \mathrm{rpm}$ for $15 \mathrm{~min}$, the clear supernatant is collected, and then the methanol is evaporated in a rotary evaporator at $45{ }^{\circ} \mathrm{C}$ under reduced pressure. Crude extract $(23.5 \%$, w/w $)$ is kept at $20{ }^{\circ} \mathrm{C}$ tell further using. Pomegranate peel extract $(500 \mathrm{mg} / \mathrm{kg})$ is administered orally in aqueous solution once per day.

\section{Experimental design:}

The animals will be divided into three groups; the first group, 20 animals, control (sham, non-diabetic) group (given normal saline solution).

The second and third groups, 40 animals, will be model groups and subjected to induction of diabetes. The second group, untreated diabetic rats, (given normal saline solution).

The third group, pomegranate peel extract treated diabetic rats (given pomegranate peel extract 500 $\mathrm{mg} / \mathrm{kg}$ body weight orally in aqueous solution once per day). The biomedical parameters are evaluated at 4,8 , 16,24 and 40 weeks after induction of diabetes [23, 24].

At the end of the experimental period, the animals are killed under light anesthesia and the kidneys are sampled and fixed for further histological, immuno-histochemical and ultrastructural examination. 


\section{Biomedical analysis:}

Biomedical parameters are evaluated at 4, 8, 16, 24 and 40 weeks after induction of diabetes. Blood samples are collected from the tail veins of rats.

Serum glucose, triglycerides (TG) and total cholesterol (TC) are measured using commercial kits and an automatic analyzer. Determination of glaciated hemoglobin is made using the affinity chromatography method [25].

\section{Histo-pathological analysis:}

The kidney is sampled by routine histological procedures and stained with:

- Hematoxylin \& eosin (H \& E) and (Mallory) stain for histo-pathological observation.

- Periodic acid-Schiff (PAS) to stain the basement membrane of blood vessels.

\section{Immunohistochemical studies:}

Three to Four-micrometer thick kidney sections will be cut, dehydrated and subsequently stained by immune-histo-chemical methods as described by [26].

Staining was performed using Immunohistochemistry stainer (DAKO Auto stainer Link48 - Serial NO: As1217D0904) a standard avidin- biotin peroxidase complex (ABC) method [27]. The Ki-67 proteins expression were examined using Ki-67 antibodies with dilution 1: 200 and $3 \mu \mathrm{g} / \mathrm{ml}$ for $30 \mathrm{~min}$. at room temperature respectively (Lab Vision Corporation, USA). With reference to the manufacturer's specifications, these antibodies reacts broadly with all known Ki-67 variants of human, rat and mouse origin by immunohistochemistry. Each set of experiments included a positive control and ensured the reproducibility of the staining process. A negative control, in which the primary antibody was omitted, was also included in each set of experiments. The positive localization result was nuclear staining in two markers (Ki-67).

Each section was counted manually at high power (X400) after identifying at low power (x100) the representative areas with the highest concentration of stained cells according to the recommendation of [28], about 1000 cells/slide were counted in each of five microscopic fields from well-labeled areas to determine the average of Ki-67 labeling index (LI). LI was expressed as number of labeled cells (positive for stain) as a percentage of the total number of cells counted in each specimen. All identifiable staining was regarded as positive.

\section{Transmission electron microscope:}

One-micrometer thick sections will be prepared from the kidney and examined with a Transmission electron microscope to evaluate:

- Thickness of basement membrane of kidney blood vessels.

- Glomerular and tubule-interstitial injury.

\section{Statistical analysis:}

The numerical data will be fed into a programmed computer for doing the statistical analysis; standard deviations and T- test [29].

\section{RESULTS}

Histo-pathological studies:

The microscopic examination of the kidney in the control group showed normal renal structures including glomerular tuft with Bowman space, renal tubules and interstitium (Fig.1 A \& B).

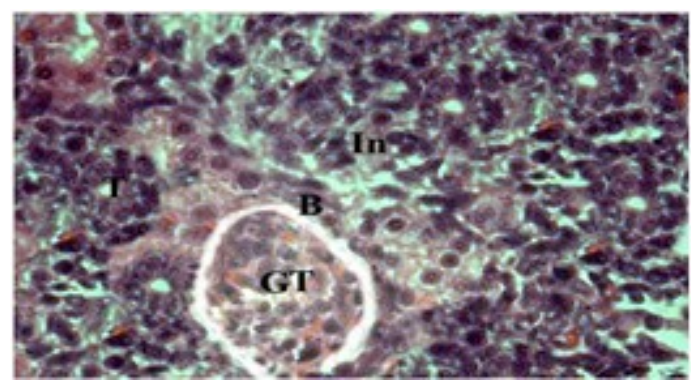

(Fig. 1 A) A photomicrograph of transverse section in the control rat kidney showed normal Glomerular Tuft (GT) with Bowman space (B), Renal Tubules (T) and Interstitium (In). (H\&E X 400). 


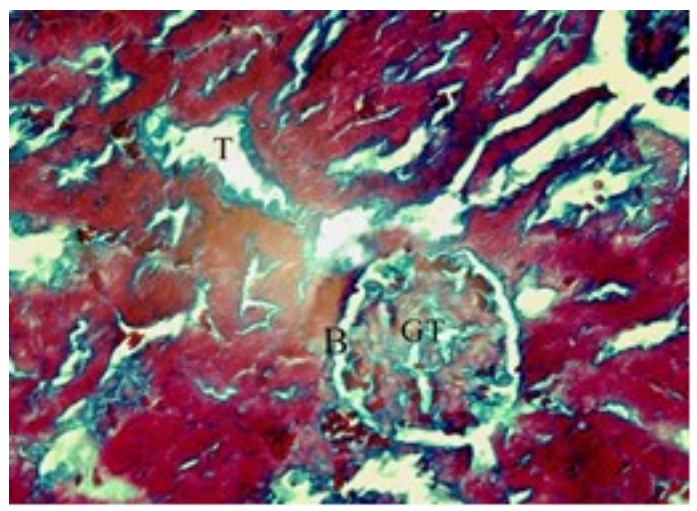

(Fig.1 B) A photomicrograph of transverse section in the control rat kidney showed normal Glomerular Tuft (GT) with Bowman space (B), Renal Tubules (T).

(Mallory X 400)

The diabetic group showed marked deteriorative changes, the kidney showed an increased mesangial matrix forming a cellular nodule (nodular glomerulosclerosis), area of mesangiolysis, thickening of Bowman's capsule as well as tubular atrophy and interstitial tissue mononuclear inflammatory infiltration (Fig. 2 A \& B).

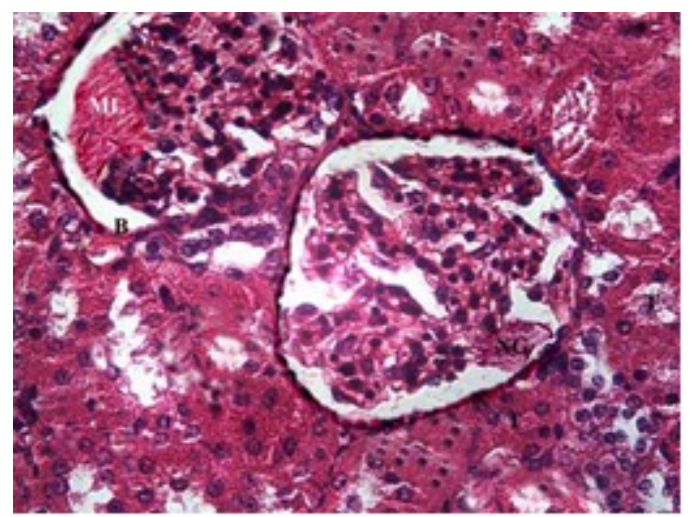

(Fig. 2 A) A photomicrograph of transverse section in diabetic rat kidney showed Nodular Glomerulosclerosis (NG), area of MesangioLysis (ML), thickening of Bowman's capsule (B) Tubular atrophy $(T)$ interstitial tissue mononuclear Inflammatory infiltration (In).

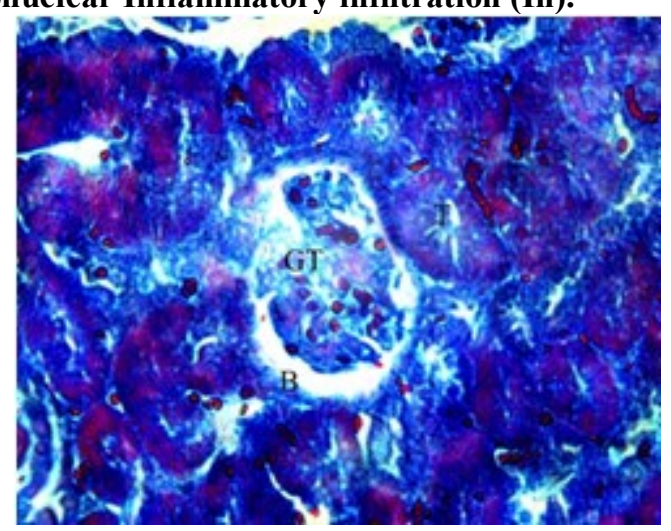

(H\&E X400)

(Fig. 2 B) A photomicrograph of transverse section in diabetic rat kidney showed fibrosis and shrinkage of glomerular tuft (G), thickening of Bowman's capsule (B) Tubular atrophy (T). (Mallory X400)

Investigations of the specimens of the treated group revealed an improving effect on the renal parenchyma indicated by healed glomerular tuft with normal thickness of Bowman capsule, healed renal tubules and healed interstitium (Fig. 3 A \& B) 


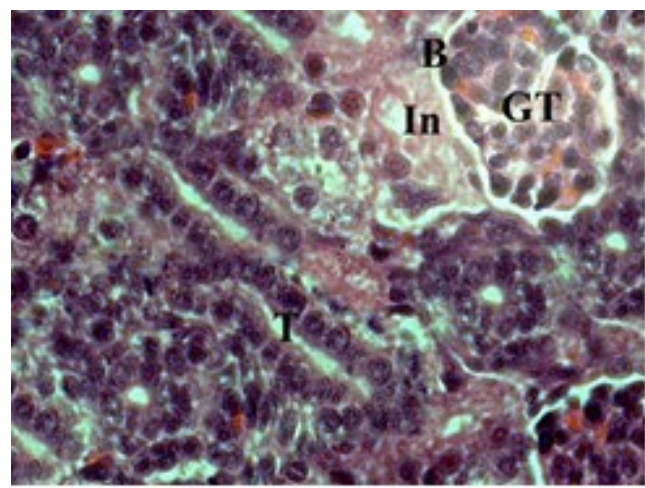

(Fig. 3 A) A photomicrograph of transverse section in treated rat kidney showed healed Glomerular Tuft (GT) with normal thickness of Bowman capsule (B), healed renal Tubules (T) and healed Interstitium (In). (H\&E 400).

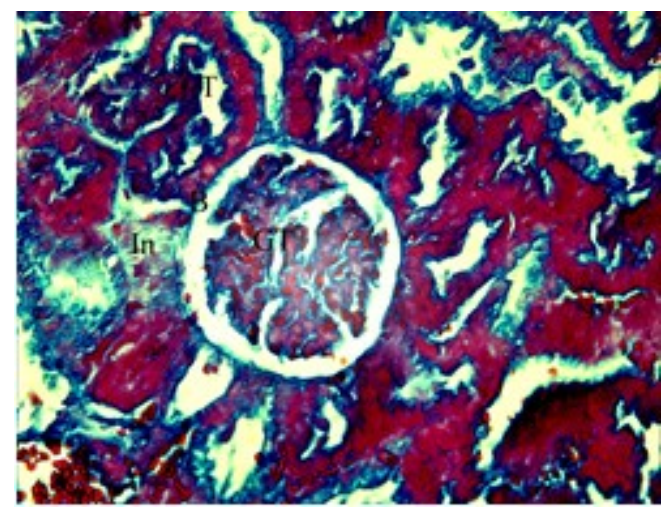

(Fig. 3 B) A photomicrograph of transverse section in treated rat kidney showed healed Glomerular Tuft (GT) normal thickness of Bowman capsule (B), healed renal Tubules (T) healed Interstitium (In). (Mallory X400)

On the other hand, control rat kidney showed normal positive reaction of PAS, normal glomerular tuft with normal Bowman space and renal tubules.

On the contrary the diabetic group revealed marked decrease in PAS reaction with shrinkage glomerular tuft, thickening of the Bowman's capsule as well as tubular atrophy.

Whereas the treated group demonstrated normal positive reaction of PAS duo to an improving effect of pomegranate on the renal parenchyma indicated by healed glomerular tuft and tubular epithelium cells (Fig. 4 A, $\mathrm{B}, \mathrm{C}$ respectively).

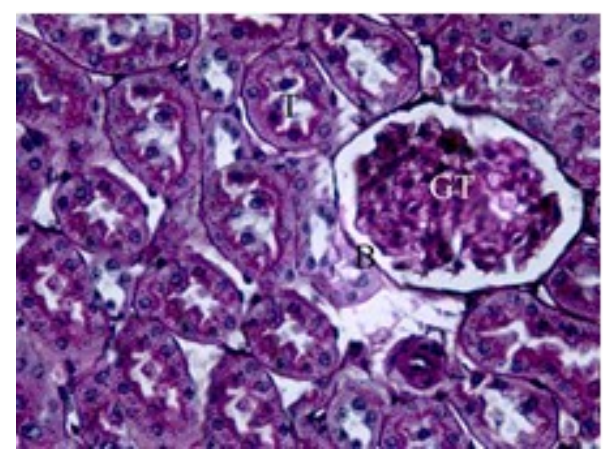

(Fig. 4 A) A photomicrograph of transverse section in control rat kidney showed normal positive reaction of PAS, normal Glomerular Tuft (GT) normal Bowman space (B) normal Renal Tubules (T). (Periodic acid-Schiff's $X$ 400) 


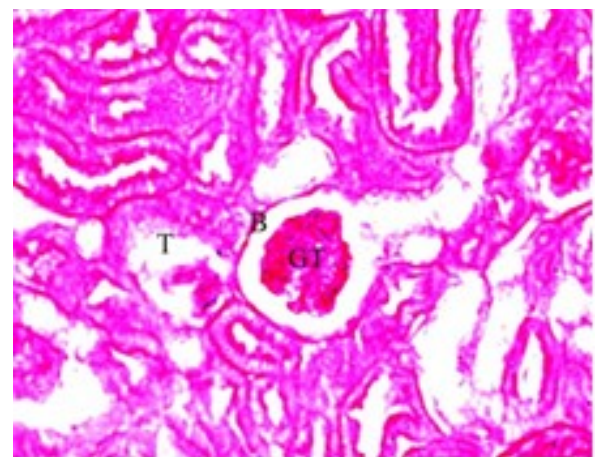

(Fig. 4 B) A photomicrograph of transverse section in diabetic rat kidney decrease in PAS reaction, shrinkage glomerular tuft (GT), thickening of the Bowman's capsule (B) Tubular atrophy (T). (Periodic acid-Schiff's X 400).

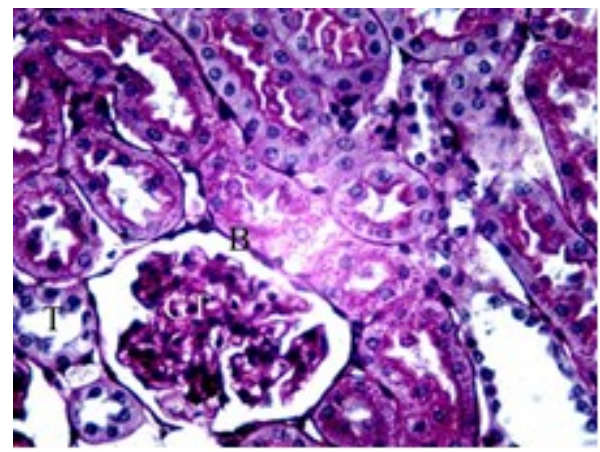

(Fig. 4 C) A photomicrograph of transverse section in treated rat kidney showed normal positive reaction of PAS with healed Glomerular Tuft (GT) normal tubular epithelium cells (T). (Periodic acidSchiff's X 400)

Immunohistochemical studies:

The Immunohistochemical examination of the kidney in the control rat group showed negative staining of ki-67 in most of cells of the kidney, while section of kidney of the diabetic rat group reveled strong staining of ki-67 in most of cells of the kidney. On the other hand section of kidney of the treated rat group showing faint immunoreactivity of ki-67 in nuclei of some cells of the kidney ( Fig. 5 A,B,C).

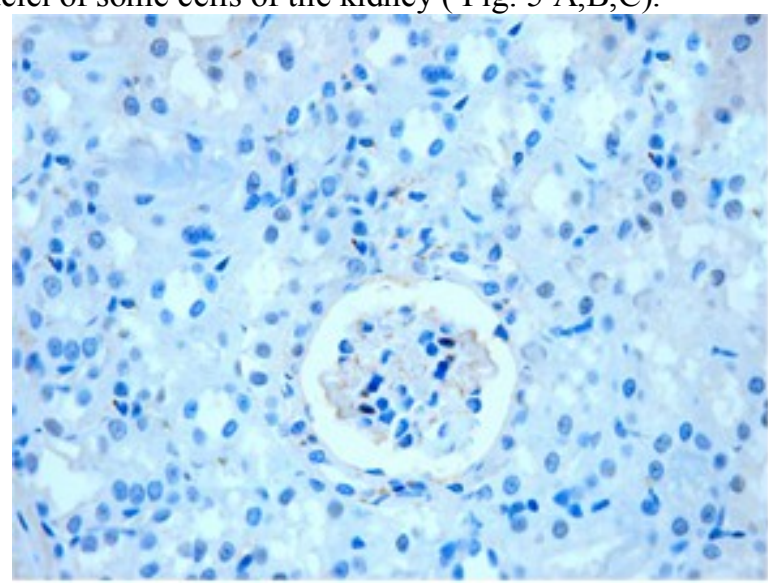

(Fig. $5 \mathrm{~A}$ ): Section of kidney of the control rat group showing negative staining of ki-67 in most of cells of the kidney. (Immunohistochemical stain ;X400). 


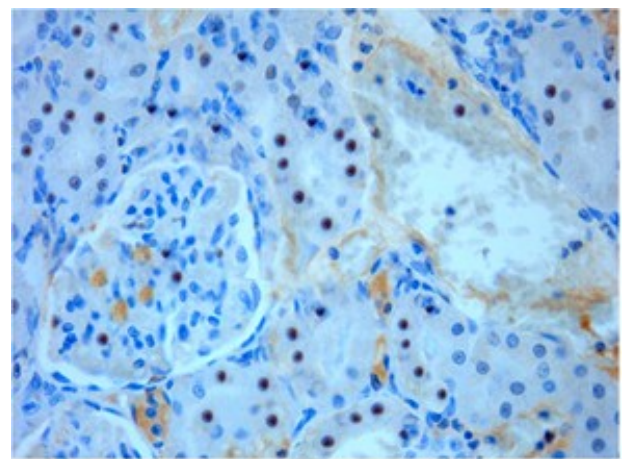

(Fig. 5 B): Section of kidney of the diabetic rat group showing strong staining of ki-67 in most of cells of the kidney. (Immunohistochemical stain ;X400).

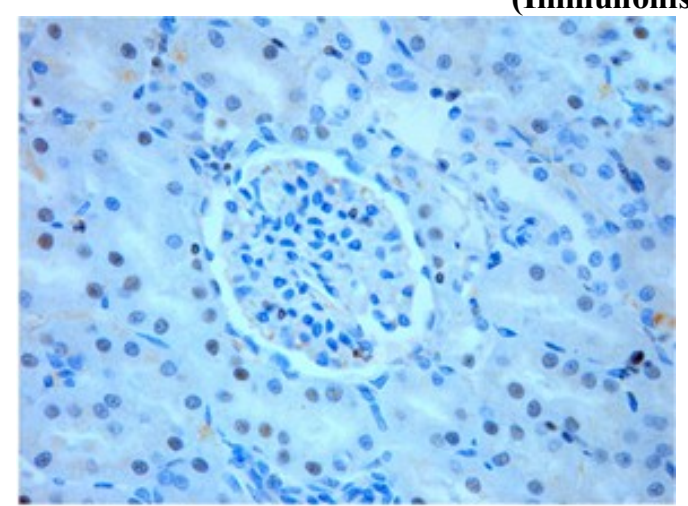

(Fig. 5 C): Section of kidney of the treated rat group showing faint immunoreactivity of ki-67 in nuclei of some cells of the kidney. Ultrastructural studies: (Immunohistochemical stain ;X400).

Ultrastructural investigations of the control group showed normal mesangial cells with normal regular intercellular matrix (Fig.6 A). The glomerular cells revealed normal numerous mitochondria and other cytoplasmic organelles as well as intact glomerular capillary wall of normal thickness (Fig.6 B). The renal tubular cells have intact basal nuclei, numerous mitochondria and intact cell membranes (Fig. 6 C).
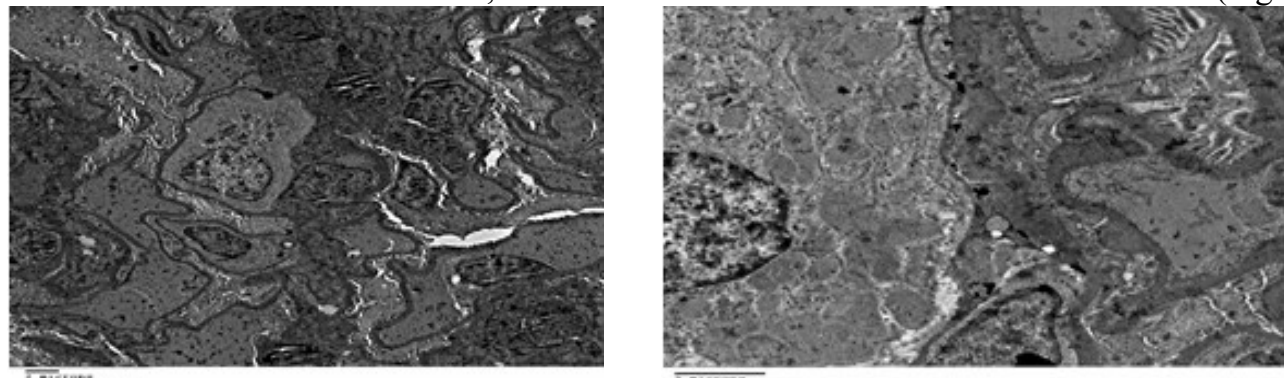

A

$\mathrm{B}$

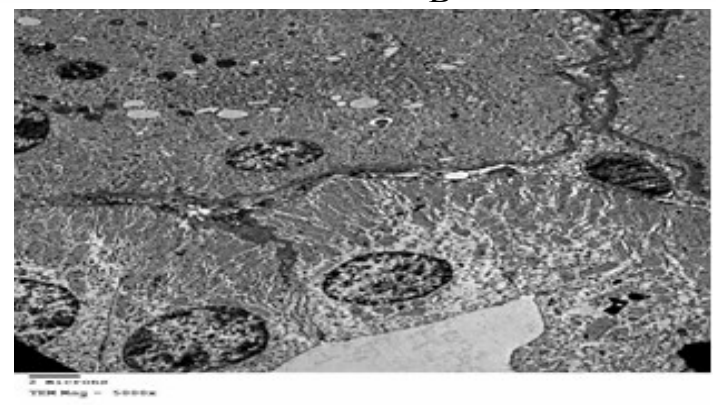

C

(Fig. 6) TEM image in normal rat kidney showed: (A) normal mesangial cells with normal regular intercellular matrix (EM x 4000). (B) Normal glomerular cells (EM x 10000). (C) Normal renal tubular cells (EM x 5000). 
Regarding the diabetic group, it showed mesangial expansion evidenced by a nodular increase in the extracellular mesangial cell material, the width of interspace exceeds two mesangial cell nuclei in at least two glomerular lobules (Fig.7 A). This was accompanied by accumulation of collagen fibrils, small lipid particles and cellular debris with destruction of the normal structure of glomerular tuft (Fig. 7 B). Also it revealed concomitant tubular basement membrane thickening of non-atrophic tubules and interstitial fibrosis. Moreover, a hyalinized thickening of the glomerular capillary wall due to intramural accumulations of imbibed plasma proteins and lipids was observed (fig.7 C).
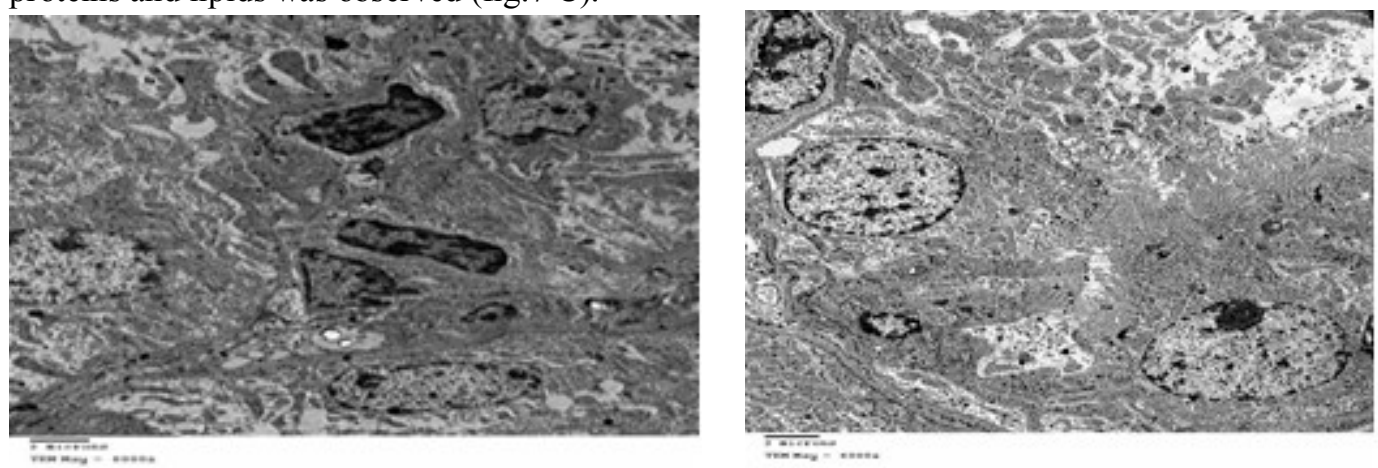

A B

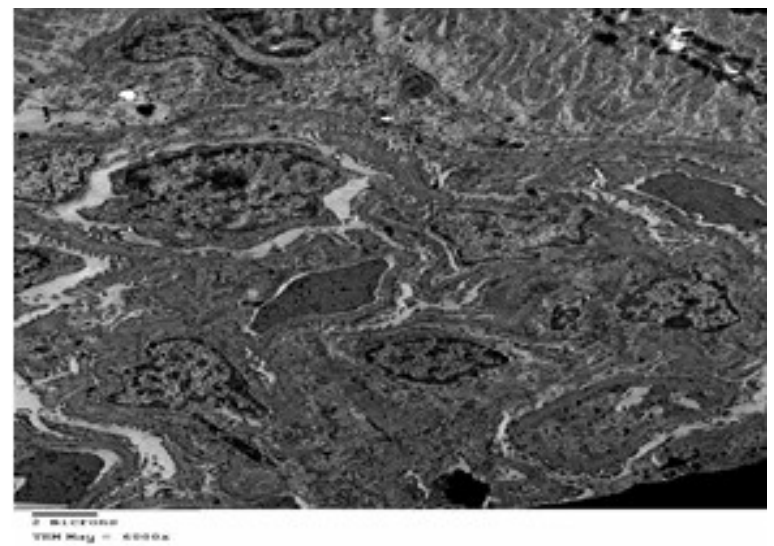

C

(Fig. 7) TEM image in diabetic rat kidney showed: (A) expansion of mesangial cells (EM x 6000). (B) accumulation of collagen fibrils, small lipid particles and cellular debris the intercellular matrix (EM $x$ 6000). (C) thickening of basement membrane of non-atrophic tubules with thickening of the glomerular capillary wall (EM x 6000).

Concerning the pomegranate treated group, it revealed an improved mesangium with disappearance of the collagen fibrils, lipid particles and cellular debris (Fig. 8 A). It showed restoring the normal glomerular tuft structure as well as the normal glomerular capillary wall thickness (Fig. 8 B \& C). Also the treated group showed a normally restored tubular basement membrane thickness after the pomegranate therapy (Fig. 8 D).

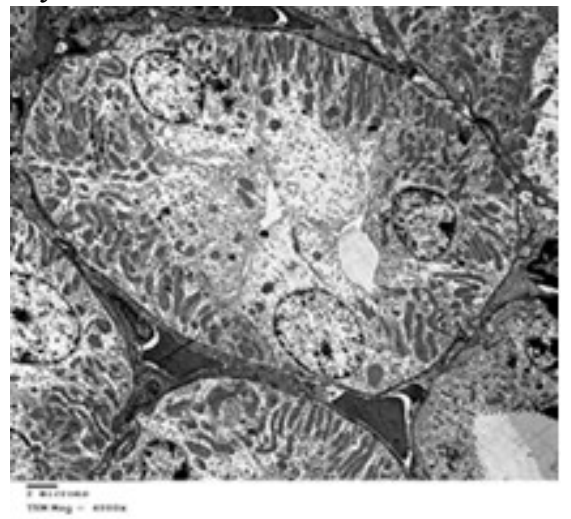

A

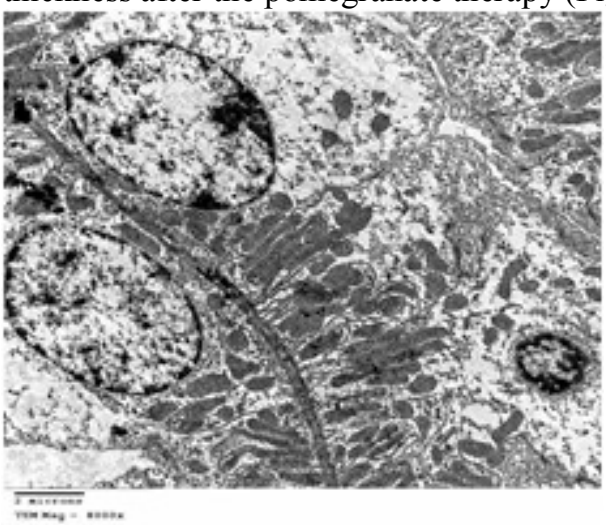

B 


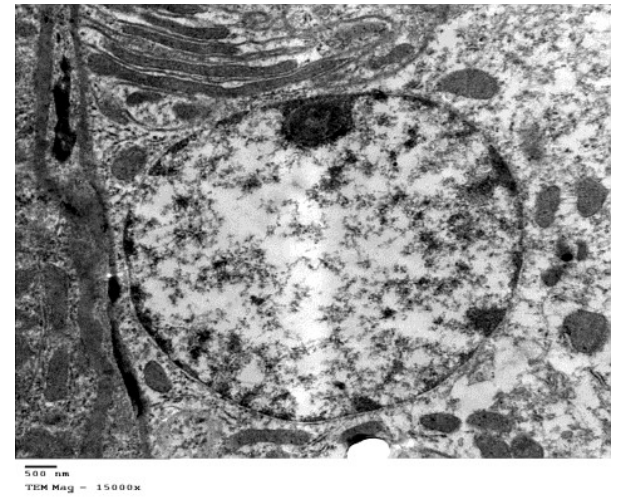

C

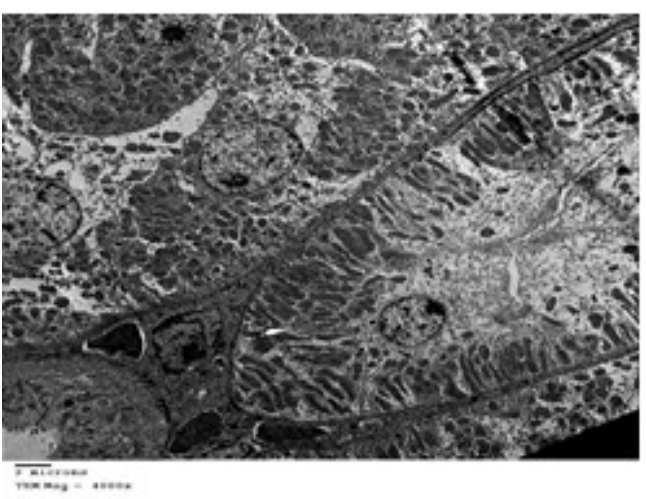

D

(Fig. 8) TEM image in pomegranate treated rat kidney showed: (A) improved mesangium (EM x 4000). (B) restoring the normal glomerular tuft structure (EM $x$ 800). (C) restoring normal glomerular capillary wall thickness (EM x 15000). (D) restored tubular basement membrane thickness (EM x 4000).

\section{Biomedical analysis:}

A) Blood level of glucose:

The blood level of glucose ranged from $72.45 \mathrm{mg} / \mathrm{dl}$ to $82.9 \mathrm{mg} / \mathrm{dl}$ with a mean of $76.84 \mathrm{mg} / \mathrm{dl}$ in the control group, while in diabetic group, it was the highest levels and ranged from $252.67 \mathrm{mg} / \mathrm{dl}$ to $294.6 \mathrm{mg} / \mathrm{dl}$ with a mean of $270.37 \mathrm{mg} / \mathrm{dl}$. The treated group was higher than the control group, while it was lower than the diabetic group. There was highly statistically significant difference between groups as regards the mean diameter, $\mathrm{P}<0.001, \mathrm{~F}$ value $=2261.1$ (Anova test $)($ table 1 and graph1) .

\section{B) Total cholesterol in the blood:}

The highest blood level of total cholesterol was in the diabetic group with a range from $190.46 \mathrm{mg} / \mathrm{dl}$ to $214.1 \mathrm{mg} / \mathrm{dl}$ with a mean of $202.31 \mathrm{mg} / \mathrm{dl}$. However the treated group showed improvement in the blood level of total cholesterol and ranged from $152 \mathrm{mg} / \mathrm{dl}$ to $174.92 \mathrm{mg} / \mathrm{dl}$ with a mean of $164.62 \mathrm{mg} / \mathrm{dl}$.

There was highly statistically significant difference between groups as regards the mean diameter, $\mathrm{P}<0.001, \mathrm{~F}$ value $=1323.9$ (Anova test) $($ table 2 and graph 1$)$.

\section{C) Triglycerides in the blood:}

The treated group showed reduction in the blood level of triglycerides as compared to the diabetic group with a range from $99 \mathrm{mg} / \mathrm{dl}$ to $135 \mathrm{mg} / \mathrm{dl}$ with a mean of $123.5 \mathrm{mg} / \mathrm{dl}$. The diabetic group showed the highest blood level of triglycerides and ranged from $153 \mathrm{mg} / \mathrm{dl}$ to $168 \mathrm{mg} / \mathrm{dl}$ with a mean of $161.45 \mathrm{mg} / \mathrm{dl}$. There was highly statistically significant difference between groups as regards the mean diameter, $\mathrm{P}<0.001, \mathrm{~F}$ value $=$ 1398.2 (Anova test) (table 3 and graph1).

Table (1): Means of blood level of glucose in $\mathrm{mg} / \mathrm{dl}$ and their statistical analysis for all groups:

\begin{tabular}{|c|c|c|c|c|}
\hline Group & $\begin{array}{l}\text { Mean } \\
\mu \mathrm{m}\end{array}$ & $\begin{array}{l}\text { Std. } \\
\text { Deviation }\end{array}$ & Versus & $\mathbf{p}$ \\
\hline Control group & 76.84 & \pm 3.44 & & \\
\hline Diabetic group* & 270.37 & $\pm \mathbf{1 1 . 9 4}$ & $\begin{array}{l}\text { Any of the other studied } \\
\text { groups }\end{array}$ & $<0.001$ \\
\hline Treated group** & 163.07 & \pm 9.73 & 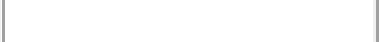 & \\
\hline
\end{tabular}

* High statistically significant increase in the diabetic group as compared to any of the other studied groups, $\mathrm{P}<$ 0.001 (Post-Hoc test).

** Significant decrease in the treated group as compared to the diabetic group, $\mathrm{p}<0.05$ (Post-Hoc test). 
Table (2): Means of blood level of total cholesterol in $\mathrm{mg} / \mathrm{dl}$ and their statistical analysis for all groups:

\begin{tabular}{|l|l|l|l|l|}
\hline Group & Mean & $\begin{array}{l}\text { Std. } \\
\text { Deviation }\end{array}$ & Versus & P \\
\hline Control group & $\mathbf{9 8 . 0 3}$ & \pm 4.37 & & \\
\hline Diabetic group* & $\mathbf{2 0 2 . 3 1}$ & \pm 8.04 & $\begin{array}{l}\text { Any of the other studied } \\
\text { groups }\end{array}$ & $<0.001$ \\
\hline Treated group** & $\mathbf{1 6 4 . 6 2}$ & \pm 6.52 & & \\
\hline
\end{tabular}

* High statistically significant increase in the diabetic group as compared to any of the other studied groups, $\mathrm{P}<$ 0.001 (Post-Hoc test).

** High statistically significant decrease in the treated group as compared to the diabetic group, $\mathrm{P}<0.001$ (PostHoc test).

Table (3): Means of the blood level of triglycerides in $\mathrm{mg} / \mathrm{dl}$ and their statistical analysis for all groups:

\begin{tabular}{|l|l|l|l|l|}
\hline Group & Mean & Std. Deviation & Versus & P \\
\hline Control group & 66.05 & \pm 4.12 & & \\
\hline Diabetic group* & 161.45 & \pm 4.82 & $\begin{array}{l}\text { Any of the other studied } \\
\text { groups }\end{array}$ & $<0.001$ \\
\hline Treated group** & 123.5 & \pm 7.66 & & \\
\hline
\end{tabular}

* High statistically significant increase in the diabetic group as compared to any of the other studied groups, $\mathrm{P}<$ 0.001 (Post-Hoc test).

** High statistically significant decrease in the treated group as compared to the diabetic group, $\mathrm{P}<0.001$ (PostHoc test).

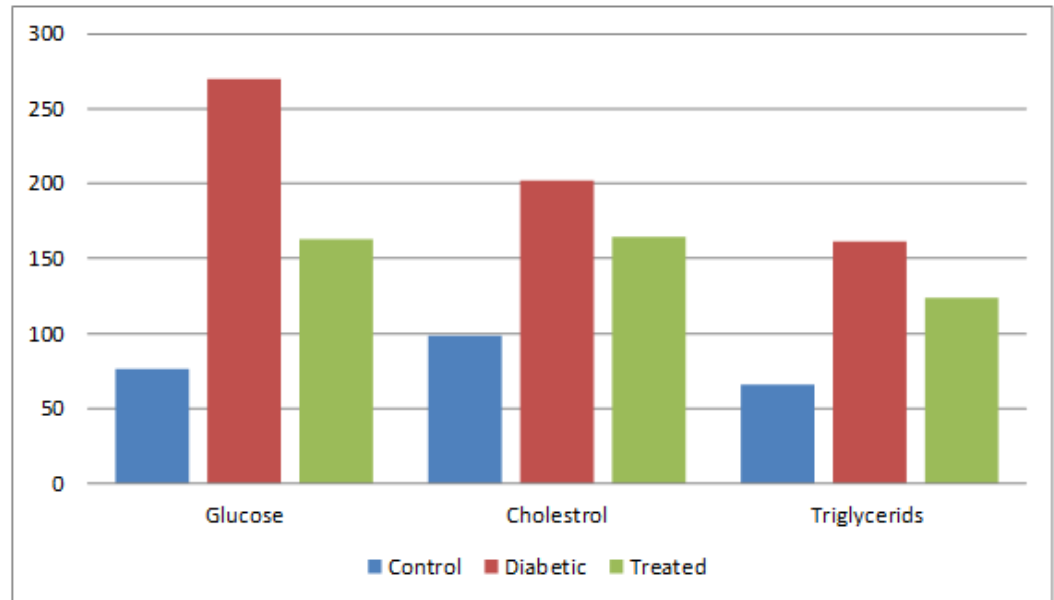

Graph (1): Comparing variations in levels of glucose, cholesterol and triglycerides in the three studied groups

\section{Discussion}

In recent years, naturally occurring anti -diabetic, anti - inflammatory and anti-oxidant compounds present in the diet consumed by humans have gained considerable attention by several researches. [30-37].

The present study was designed to examine, for the first time according to the available literatures, the possible preventive effects of pomegranate peel extract on the structures of renal tissue of diabetic kidney as one of the edible safe natural products and the results were wonderful.

According to the histo-pathological investigations of the present results pomegranate peel extract leads to an improving effect on the renal parenchyma in diabetic kidney indicated by healed glomerular tuft, healed renal tubules and healed tubular interstitial epithelial cells supported by normal positive reaction of PAS. At the ultrastructural level, the present observations revealed improving mesangium with disappearance of the collagen fibrils, lipid particles and cellular debris. Also it showed restoring the normal glomerular tuft structures as well as the normal glomerular capillary wall thickness and normally tubular basement membrane thickness after the pomegranate therapy. 
These findings are in agreement with many studies in recent years that demonstrated a correlation between the role of pomegranate peel extract and juice in regulating vital cellular functions, including cell proliferation and differentiation and its potent antioxidant activity and free radical scavenging capability $[16,18,33,34,35,38$ and 39$]$.

One key mechanism by which pomegranate fractions affect the type 2 diabetic condition is by reducing oxidative stress and lipid peroxidation. This reduction may occur by directly neutralizing the generated reactive oxygen species, increasing certain antioxidant enzyme activities, inducing metal chelation activity, reducing resistin formation, and inhibiting or activating certain transcriptional factors, such as nuclear factor $\mathrm{kB}$ and peroxisome proliferator-activated receptor $\gamma[18]$.

Also, of pomegranate peel extract and juice has potent antioxidative capacity against lipid peroxidation [33]. Moreover, the anticarcinogenic effect of pomegranate peel extract and juice through cell cycle regulationmediated apoptosis may play a role in amelioration of histopathological picture.

The presence of these polyphenols in the pomegranate peel may be responsible for antioxidant and anticarcinogenic effect of peel extracts [42].

Moreover the present immunohistochemical data indicates that Ki-67 is a nuclear protein which is expressed in proliferating cells. Ki-67is preferentially expressed during late G1, S, M, and G2 phases of the cell cycle, while resting, non-cycling cells (G0 phase) lack Ki-67 expression [43]. The high expression of ki-67 in diabetic group indicated that the diabetes increase cell proliferation. While, in treated group, it was noticed the low expression of ki-67, this might be due to the administration of pomegranate peel extract because it has been considered as a powerful ROS scavenger in rat through its antioxidant effects [44]. This anti-proliferative effect of propolis may be linked to its ability to regulate the expression and activity of cell cycle-related proteins [45].

Regarding the biomedical analysis, the present findings indicates that the blood glucose level was higher in the treated group than the control group, while it was lower than the diabetic group. Moreover the treated group showed improvement in the blood level of total cholesterol than the diabetic group. Also the treated group showed reduction in the blood level of triglycerides as compared to the diabetic group. All these elements showed high statistical significant difference in between the treated and the diabetic groups. These findings pass line by line with the previous reports of [46].

\section{CONCLUSION}

In conclusion, based on the present findings, it is tempting to suggest that the pomegranate peel extract may possess a strong potential for development as anti-diabetic, anti- carcinogenic, antioxidant and anti-inflammatory agents for new therapeutic that may be exceedingly effects. The use of pomegranate in general as table fruit or juice can, so, be recommended in human nutrition for all these purposes and qualities.

\section{References}

[1] Amos A. F.; McCarty D. J. and Zimmit P. (1997). The rising global of diabetes and its complications: estimates and projections to the year 2010. Diabetes Med.; 14:7- 85.

[2] Al-Nozha M.M., Al-Maatouq M.A., Al-Mazrou Y.Y. et al. (2004). Diabetes mellitus in Saudi Arabia. Saudi Med. J.; 25 (11): 1603-1610.

[3] W.ww.diabetes.co.uk, accessed on 9/10/2011.

[4] Biesenbach G. (2007). Highest mortality during the last year before and thefirst year after start of dialysis treatment in type 2 diabetic patients with nephropathy. Curr Diabetes Rev.; 3: 123-126.

[5] Schernthaner G. (2008). Kidney disease in diabetology: lessons from 2007. Nephrol Dial Transplant; 23: 1112-1115.

[6] Simonson M. S. (2007). Phenotypic transitions and fibrosis in diabetic nephropathy. Kidney Int.; 71: 846-854.

[7] Qian Y, Feldman E, Pennathur S et al. (2008). From fibrosis to sclerosis: mechanisms of glomerulosclerosis in diabetic nephropathy. Diabetes; 57: 1439-1445.

[8] Prashanth D.; Asha M. K. and Amit A. (2001). Antibacterial activity of Punica granatum. Fitoterapia; 72: 171-173.

[9] Afaq F.; Saleem M.; Krueger C. G.; Reed J. D. and Mukhtar H. (2005). Anthocyanin- and hydrolysable tannin-rich pomegranate fruit extract modulates MAPK and NF-kappa B pathways and inhibits skin tumorigenesis in CD-1 mice. Int J Cancer; 113: 423433.

[10] Bagri P.; Ali M.; Aeri V.; Bhowmik M. and Sultana S. (2009). Antidiabetic effect of Punica granatum flowers: Effect on hyperlipidemia, pancreatic cells lipid peroxidation and antioxidant enzymes in experimental diabetes. Food and Chemical Toxicology; 47:50-54.

[11] Belal S.K.M., Abdel-Rahman A.H., Mohamed D.S., Osman H.H. and Hassan N.A. (2009). Protective effect of pomegranate fruit juice against Aeromonas hydrophila-induced intestinal histopathological changes in mice. World Applied Sciences J. ; 7 (2) 142 152.

[12] Toklu H.Z.; Dumlu M. U.; Sehirli O.; Ercan F.; Gedik N.; Go"kmen V.; et al. (2007). Pomegranate peel extract prevents liver fibrosis in biliary-obstructed rats. J. Pharmacol.; 59: 1287-1295.

[13] Toklu H. Z.; Sehirli O.; Ozyurt H.; Mayadag־li A. A.; Eksiog $־$ D. E.; Cetinel S.; et al.( 2009). Punica granatum peel extract protects against ionizing radiation-induced enteritis and leukocyte apoptosis in rats. J. Radiat. Res. (Tokyo); 50: 345-353.

[14] Xu K. Z_Y.; Zhu C.; Kim M. S.; Yamahara J. and Li Y.( 2009). Pomegranate flower ameliorates fatty liver in an animal model of type 2 diabetes and obesity. J. Ethnopharmacology; 123(2): 280-287.

[15] El-Rashedy A. H.; Belal K. S.; Osman H. E. and Shehab G. M. (2011).Protective role of pomegranate on fatty liver in obesity: An experimental chemical and histopppathological study. The Egyptian Journal of Hospital Medicine; 43: 162-172. 
[16] Kam A1, Li KM, Razmovski-Naumovski V, Nammi S, Shi J, Chan K, Li GQ. (2013). Acomparative study on the inhibitory effects of different parts and chemical constituents of pomegranate on $\alpha$-amylase and $\alpha$-glucosidase. Phytother Res. Nov;27(11):1614-20. doi: 10.1002/ptr.4913. Epub 2012 Dec 19.

[17] Abdel Moneim AE1, Othman MS, Mohmoud SM, El-Deib KM. (2013): Pomegranate peel attenuates aluminum-induced hepatorenal toxicity.Toxicol Mech Methods. Oct;23(8):624-33. doi: 10.3109/15376516.2013.823634. Epub 2013 Oct 8.

[18] Banihani S1, Swedan S, Alguraan Z. (2013). Pomegranate and type 2 diabetes Nutr.Res;33(5):341-8. doi: 10.1016/j.nutres.2013.03.003. Epub 2013 Apr 15.

[19] Bullwinkel J, Baron-Lühr B, Lüdemann A, Wohlenberg C, Gerdes J, Scholzen T (2006). "Ki-67 protein is associated with ribosomal RNA transcription in quiescent and proliferating cells". J. Cell. Physiol. 206 (3): 624-35.

[20] Rahmanzadeh R, Hüttmann G, Gerdes J, Scholzen T (2007). "Chromophore assisted light inactivation of pKi-67 leads to inhibition of ribosomal RNA synthesis".Cell Prolif. 40 (3): 422-30.

[21] Waly MI, Al-Rawahi AS, Al Riyami M, Al-Kindi MA, Al-Issaei HK, Farooq SA, Al-Alawi A, Rahman MS1. (2014). Amelioration of azoxymethane induced-carcinogenesis by reducing oxidative stress in rat colon by natural extracts. BMC Complement Altern. Med. Feb 18;14:60.

[22] Lapornik B.; Prosjek M. and Wondra A. G. (2005). Comparison of extracts prepared from plant by-products using different solvents and extraction time. J. Food Eng.; 71:214-22.

[23] Abraham E. C., Perry R. E. and Stallings M. (1983). Application of affinity chromatography for separation and quantitation of glycosylated hemoglobins. Journal of Laboratory and Clinical Medicine; 102: 187-197.

[24] Malik, A., F. Afaq, S. Sarfaraz, V.M. Adhami, D.N. Syed and H. Mukhtar, (2006). Pomegranate fruit juice for chemoprevention and chemotherapy of prostate cancer. The Journal of Uorolog175: 1171-1176.

[25] Daniel W. W. Biostatistics. A foundation for analysis in the health sciences. 1995; 6th Ed. John Wiley \& Sons, Inc. New York. Chichester. Brisbane. Toronto. Singapore

[26] Coimbra T. M.; Janssen U; Gro“ ne H .J.; Ostendorf T.; Kunter U., Hartmut S., Brabant G. and Rgen F. J. (2000). Early events leading to renal injury in obese Zucker (fatty) rats with type II diabetes Kidney International; 57:167-182.

[27] Hsu S., Raine L.and Fanger H. (1981). Use of avidin-biotin-peroxidas technique: A comparison between ABC and unableled antibody (PAP) Procedures.J.Histochem.Cytochem.; 29: 577-580.

[28] Cohen L Baum A, , Hall M.(1993). Control and intrusive memories as possible determinants of chronic stress. Psychosom Med. May-Jun; 55(3):274-86.

[29] Broga, L.C., J.W.Shapp, C.Cummings,M.Jett, J.A.Takahashi, L.S.Carmo,E.Chartone-Sousa and A.M.Nascimemto(2005). pomegranate extract inhibits staphylococcus production. Journal of Ethno pharmacology, 4 (96):335-339

[30 ] Mohan M1, Waghulde H, Kasture S.( 2010). Effect of pomegranate juice on Angiotensin II-induced hypertension in diabetic Wistar rats Phytother Res. J;24 Suppl 2:S233-4.

[31] McCarrell, E.M., S.W. Gould, M.D. Fielder, A.F. Kelly and W. El Sankary and D.P. Naughton, (2008). Antimicrobial activities of pomegranate rind extracts: enhancement by addition of metal salts and vitamin C. BMC Complementary and Alternative Medicine, 15(8):64

[32] Katz SR, Newman RA, Lansky EP. (2007). Punica granatum: heuristic treatment for diabetes mellitus. J Med Food.; 10(2):213-7.

[33] Kaur G, Jabbar Z, Athar M, Alam MS (2006). Punica granatum (pomegranate) flower extract possesses potent antioxidant activity and abrogates Fe-NTA induced hepatotoxicity in mice. Food Chem Toxicol.; 44(7):984-93.

[34] Huang TH, Peng G, Kota BP, Li GQ, Yamahara J, Roufogalis BD, Li Y. (2005). Anti-diabetic action of Punica granatum flower extract: activation of PPAR-gamma and identification of an active component. Toxicol Appl. Pharmacology.;207(2):160-9

[35] Mastrodi Salgado J, Baroni Ferreira TR, de Oliveira Biazotto F, Dos Santos Dias CT. (2012). Increased antioxidant content in juice enriched with dried extract of pomegranate (Punica granatum) peel. Plant Foods Hum Nutr. Mar;67(1):39-43.

[36] Dikmen M, Ozturk N, Ozturk Y. (2011). The antioxidant potency of Punica granatum L. Fruit peel reduces cell proliferation and induces apoptosis on breast cancer. J Med Food. Dec;14(12):1638-46.

[37] Medjakovic S, Jungbauer A. (2013). Pomegranate: a fruit that ameliorates metabolic syndrome. Food Funct. Jan; 4(1):19-39. Epub 2012 Oct 12.

[38] Al-Muammar MN, Khan F. (2012): Obesity: the preventive role of the pomegranate (Punica granatum). Nutrition. :28(6):595-604. doi: 10.1016/j.nut.2011.11.013. Epub 2012 Feb 17. Review

[39] Ismail T, Sestili P, Akhtar S. (2012). Pomegranate peel and fruit extracts: a review of potential anti-inflammatory and antiinfective effects. J. Ethnopharmacol. 28;143(2):397-405. doi: 10.1016/j.jep.2012.07.004. Epub 2012 Jul 20.

[40] Jurenka JS. (2008) : Therapeutic applications of pomegranate (Punica granatum L.): a review. Altern Med Rev. Jun;13(2):128-44. Review.

[41] Li Y, Qi Y, Huang TH, Yamahara J, Roufogalis BD. (2008). Pomegranate flower: a unique traditional antidiabetic medicine with dual PPAR-alpha/-gamma activator properties.Diabetes Obes Metab. Jan;10(1):10-7. Review

[42] Gil MI, Tomas-Barberan FA, Hess Pierce B, Holcroft, DM. and Kader, A.A. (2000). Antioxidant activity of pomegranate juice and its relationship with phenolic composition and processing. Journal of Agricultural and food chemistry. 48: 4581-4589.

[43] Scholzen T, Gerdes J (2000):The Ki-67 protein: from the known and the unknown. J Cell Physiol. 182(3):311-322.

[44] Ozguner F, Armagan A, Koyu A, Calıskan S, Koylu H (2005). A novel antioxidant agent caffeic acid phenethyl ester (CAPE) prevents shock wave-induced renal tubular oxidative stress. Urol. Res., 33: 239-243.

[45] Hahm E, Jin DH, Kang JS, Kim YI, Hong SW, Lee SK, Kim HN, Jung da J, Kim JE, Shin DH, Hwang YI, Kim YS, Hur DY, Yang Y, Cho D, Lee MS, Lee WJ. (2007). The molecular mechanisms of vitamin C on cell cycle regulation in B16F10 murine melanoma. J Cell Biochem. Nov 1;102(4):1002-10.

[46] Rosenblat, M., Hayek, T., \& Aviram, M. (2006). Anti-oxidative effects of pomegranate juice (PJ) consumption by diabetic patients on serumand onmacrophages. Atherosclerosis;187: 363-371. Note that the title of the book is in lower case letters and italicized. There is no comma following the title. Place of publication and publisher are given. 